\title{
Design Strategies for Youth-Focused Pervasive Social Health Games
}

\author{
Andrew D. Miller, Jessica Pater, Elizabeth D. Mynatt \\ College of Computing \\ Georgia Institute of Technology \\ Atlanta, GA \\ \{andrew.miller, pater, mynatt\}@gatech.edu
}

\begin{abstract}
Adolescent obesity is an increasing challenge, and pervasive social health games hold much promise for promoting sustained healthy behaviors. Researchers and designers of these systems have many potential theories and existing best practices at their disposal. Our study, grounded in participatory design, shows which ones matter-both for pervasive social health games and within the cultural context of a community we studied over the course of three years. We worked with 112 US middle school students from a lower-income community in a series of participatory design exercises focused on social rewards for everyday physical activity. In our analysis, we discuss design implications in four key areas: social presence, gender effects, incentives and competition. We show how these themes manifested in students' designs and why they were particularly important to our participants. We then use our findings to suggest design strategies for youth-focused pervasive social health games.
\end{abstract}

Pervasive Health Games; Participatory Design; Children; HCI

\section{INTRODUCTION}

Adolescent obesity is an increasing challenge: in the last 30 years, adolescent obesity rates in the US alone have tripled [1]. And habits formed during adolescence can have lifelong effects: adolescent obesity is the single biggest predictor of obesity in adulthood [1]. Health promotion research shows that even the simple act of walking more each day has lasting benefits [2]. Additionally, lower physical activity levels are a key correlate of obesity in adolescence, even more so than diet [3].

Pervasive social health games are promising tools in this regard. Games can act as a shared reference and communicate values through incentive structures and rule systems [4], and social games can reward identity presentation and exploration and support daily rituals and collective experiences [5]. Moreover, the benefits of daily exercise may be multiplied when groups and communities work together to create new habits. When these are connected to a pervasive health platform, presenting a health intervention as a game can increase motivation by turning everyday exercise into something fun. This approach has been shown to be particularly helpful technique for interventions that target children and adolescents [6].

However, simply calling an application a game is not enough to guarantee success. Gamified systems that "just add points" [1], [2], [7] may lead to the design of shallow, easilyabandoned novelties[1], [8]. Understanding the perspective of the people who will ultimately use a product is critical in a health application, and even more so in a game, traditionally a leisure activity designed for fun. It is not obvious what adolescent youth want out of these experiences, and how those desires might be translated into system designs. Furthermore, researchers and designers of youth-focused pervasive social health games have many potential theories and existing best practices at their disposal, and choosing which to focus on can be challenging.

Over the last three years, our team has worked with groups of middle school students to help answer these questions. We focus on a population at risk to become overweight or obese: minority students from lower-income urban communities [1], [2], [9]. We have worked with these students in participatory design exercises as they created concepts for health games that they would like to play. In the most recent iteration, in the month leading up to the design exercises, students used a pedometer-based social health platform and then worked in groups to design games that could be deployed on that platform. We analyzed their game designs to look for trends and design priorities, and compared these designs to the results from the past two years.

Our study, grounded in participatory design, shows which ones matter-both for pervasive social health games and within the cultural context of the community we studied. This paper provides design implications in four key areas: social presence, gender effects, incentives and competition. We show how these themes manifested in students' designs and why they were particularly important to our participants. We then use our findings to suggest design strategies for youth-focused pervasive social health games. Our paper contributes an evidence-based set of design strategies that both designers and researchers in this area can put to use.

\section{RELATED WORK}

The work presented in this paper touches several research threads in the HCI and Pervasive Health communities. In this section, we focus on related work in obesity prevention, health games for youth, designing for and with children, and health disparities as they relate to HCI.

\section{A. Obesity prevention in HCI research}

In recent years, the HCI community has devoted serious attention to obesity prevention interfaces and systems. Much of this work focuses on individual health goals for adults, augmented by tracking and visualization technologies. For 
example the Ubifit Garden project showed participants a passive visualization of their own physical activity on their cellphone wallpapers. The more activity they did throughout the day, the taller the plants and flowers grew [1], [3], [10]. This approach has since been integrated into commercial products; the Fitbit pedometer shows a similar visualization at the press of a button [4], [11] Others have focused on social and peer influence in obesity prevention. Consolvo et al.'s Houston, for example, provided a small group of friends a view of each others' step counts [5], [12]. Fisn'n'Steps provided an ambient fishbowl visualization in an office environment; as participants took more steps throughout the day, their fish increased in size[6], [13].

\section{B. Health games for youth}

However, most interventions for youth present themselves as games, employing competition frameworks along with friendly avatars and cartoon worlds. Berkovsky et al's Play, Mate! system, for example, leveraged a marble game mechanic; as participants moved their bodies a marble moved through a 3D world towards a goal point [14]. Many youthfocused interventions focus on children or adolescents living with chronic conditions, such as Bers' Zora, a virtual world designed to promote civic discourse but which has been used to conduct virtual therapy sessions for transplant recipients [15][17]. Lieberman's Packy \& Marlon (one of the earliest videogames for health) replicated popular Mario Bros. - style platform gameplay to teach young diabetics declarative and procedural knowledge about everyday insulin management strategies [18].

While many health games are console based (like Packy \& Marlon), others involve physical activity as part of play. These 'exertion interfaces' [19] encourage physical activity through real-time movement. Play, Mate! used the Nintendo Wii console to sense players' movements and mirror them with an on-screen player [14]. Many commercial systems use this method, and now with the XBOX Kinect, players' motions can be sensed without any on-body apparatus.

Pervasive health games are a recent advance, incorporating sensed physical activity into a digital game world shared by groups of children. The American Horsepower Challenge (AHPC), a month-long pedometer challenge for middle school students, tracks steps as a proxy for overall activity [20], as do many prior pervasive health studies in the HCI literature [10], [13]. Step counts have been shown to correlate with physical activity in adults [12], and this correlation has been shown to hold for children and adolescents as well [21].

\section{Designing for and with children}

Our research draws on and contributes to a rich tradition of interaction design for and with children. We have been particularly influenced by the Participatory Design movement, in which end-users are involved throughout the design process rather than merely as testers. Participatory Design views users as key stakeholders, and technical systems as "networks of people, practices, and technology embedded in particular organizational contexts" [22]. Participatory Design is often used to design for and with populations traditionally left out of the design process, with an emphasis on designing in the wild as opposed to in a laboratory setting [23].

In HCI design for children, this often means working with schools, nonprofits, camps or after-school programs-forming a partnership with an organization or group of participants over the course of a design project. In such projects, children can be involved merely as end users (no involvement), as testers, as informants, or as design partners (full involvement) [24]. In our research, we work with children as informants, working closely with them in phases, then designing mockups and prototypes, then reflecting these back to the participants for iterative feedback throughout the project. We also deployed a system as a technology probe, a common strategy in designing for and with children [25].

However, while many researchers employ participatory design with children, field deployments and evaluation in an authentic context are less common. In a survey of a decade of papers published in the Interaction Design for Children (IDC) conference, Yarosh et al. found only $6 \%$ of papers designed and evaluated in an authentic context, and only $31 \%$ of studies that tested systems involved children as design partners or informants [26]. Researchers in this area have called for broadening childrens' involvement as design partners, particularly middle-school aged adolescents [27].

\section{Addressing health disparities through HCI}

A growing number of researchers in the HCI community are examining health as an ecological issue, based on evidence from health promotion research that socio-economic disparities are reflected in healthcare and population healthiness [9]. In this context, Parker et al. argue that health promotion for lowerSES (lower socioeconomic status) communities can be seen as activism. Using this lens, they also believe that HCI health disparities research should involve participants as a community, not just a collection of users [28], [29]. Maitland et al. have shown that in some cases the typical health promotion rhetoric of persuasion may not be the best fit for lower-SES populations, where the operative challenge may be one of access not persuasion, and systems focused on resource awareness can be powerful tools for addressing health disparities through HCI [30]. More broadly, Yardi and Bruckman argue that the new 'typical' HCI user is less likely to be white and middle class, calling on us as a community to explicitly design for low-SES and minority users [31].

\section{METHODS}

To understand how middle-school students from a lowerincome community might design a pervasive social health game, over the last three years we conducted participatory design exercises at a summer day camp with 112 middle school students from a public school district in the Atlanta area. In 2012, we also deployed a social pedometer platform for three weeks leading up to the camp. In our participatory design sessions, students worked in small groups of three to five students to design a social game for health that they and their friends would want to play. We also conducted focus groups and informal interviews, distributed surveys and collected field notes about the students' designs and design priorities. We then 
analyzed the students' designs using iterative inductive qualitative analysis.

\begin{tabular}{|l|l|l|l|}
\hline Year & Students & Games & Method/Data \\
\hline 2010 & $\begin{array}{l}39 \\
(22 \mathrm{~m} / 17 \mathrm{f})\end{array}$ & 9 & $\begin{array}{l}\text { 1-day participatory design } \\
\text { (prototypes + presentations) }\end{array}$ \\
\hline 2011 & $\begin{array}{l}45 \\
(18 \mathrm{~m} / 27 \mathrm{f})\end{array}$ & 14 & $\begin{array}{l}\text { 2-day participatory design } \\
\text { (posters + skits) }\end{array}$ \\
\hline 2012 & $\begin{array}{l}28 \\
(14 \mathrm{~m} / 14 \mathrm{f})\end{array}$ & 7 & $\begin{array}{l}\text { 3-week technology probe, } \\
\text { 2-week participatory design } \\
\text { (videos) }\end{array}$ \\
\hline
\end{tabular}

Table 1. Summary of methods and participants by year.

\section{A. Participants}

Over the last three years, 112 students from three middle schools in the same school district participated in our study. The racial demographics of these three schools were very similar: 80\% African American, 9\% Hispanic, 9\% Caucasian and $2 \%$ Asian. Students were drawn from schools in lowerincome neighborhoods where at least $40 \%$ of students qualify for free or reduced lunch (known as Title 1 Schools). Students were invited to participate in the camp by teachers and administrators, who we asked to choose a mix of students representative of the school as a whole. The Average Adjusted Gross Income of households in the catchment area is approximately $\$ 38,700$, and the crime index is almost double that of the state average [22]. Over the three years, $57 \%$ of participants were female and $43 \%$ were male.

\section{B. Participatory design exercises}

In our participatory design exercises, we played the role of client. Students' presentations took the form of advertisements or trailers to convince their peers to play and to convince us to fund the project and build their game. When a group was ready for an intermediate feedback round, we would have them run through their current presentation and give them suggestions for improvements.

Although the design brief and general process has been similar each time, we have expanded the scope of the exercise each year. In 2010, the exercise took place during one day (about four hours), with students designing in the morning and presenting their designs in the afternoon. In 2011, we expanded the exercise to cover two days (about eight hours) and to include a round of review. In 2012, students spent about 14 hours on the project across seven days, with multiple rounds of feedback. We also evolved the design strategies we employed. Inspired by the Neighborhood Networks project [32], in 2010 and 2011 we focused on physical prototyping, giving students a variety of foam blocks and craft supplies. Students presented their work to each other through presentations that included skits of their games being played. In 2012, students spent the first week designing their games, and the second week shooting and editing three- to four-minute movies using Apple iPads. The movies were shown on the last day of the camp. Each student also received a DVD copy of the videos to take home. The videos described students' games and showed simulated gameplay.

\section{Social pedometer platform development}

In the Spring of 2012, prior to attending camp students also used a pedometer-based social fitness site we designed called StepStream. Each student received a pedometer-we used GeoPalz pedometers that store 20 days of activity and can be shoe or waist-mounted - and created an account on the system. Each day, they received an SMS reminder and entered the number of steps they earned; each entry generated a post on the site that other students could favorite or comment on. Raw step counts were hidden from other students; instead, the posts reported "activity points," which are relative to a student's typical day. If they chose, students could link their phone to the system for daily reminders and to enter their steps by SMS. StepStream was open only to study staff and participating students, and was developed on top of the microblogging platform StatusNet.

In the version deployed for this study, StepStream lacked a game or other social incentive structure. We designed it this way to allow students to create their own game concepts during the participatory design exercises. In this way, the system served as a guide for ideation - a platform upon which the students could design their games, allowing them to be creative when it came to gameplay but providing a baseline physical activity component so they could focus on games beyond exertion interfaces.

\section{Analysis}

The thematic findings presented in this paper are drawn principally from our iterative inductive analysis of the students' game designs. We recorded photos, audio and videos of each group's presentation across the three Summer Extravaganza camps, and took field notes about our impressions during the camps. In 2012, because of the increased exposure to the students, we were often able to supplement the students' official videos with additional information based on informal interviews and the iterative feedback sessions during camp. We used all of this information during our analysis. Each member of the research team re-watched the videos and took notes on the game's themes and characteristics. Then we discussed emergent themes we had seen individually, agreed on a common set, and individually re-coded each presentation based on those themes. We then met again to rationalize our themes and re-applied them to each game design.

\section{Findings: DESIGN STRATEGIES}

Our participatory design studies over the last three years generated a fascinating set of game designs, from fighting princesses to virtual pets. But they also reveal the students' priorities, knowledge and desires with respect to pervasive social health games. In this section, we describe the four most salient characteristics of such systems: social presence, incentives, gender effects and competition. Grounded in our analysis of the students' designs, we show why these themes mattered for our participants. We then offer evidence-based design strategies for future youth-focused pervasive social health games. 


\section{A. Social Presence}

A key benefit of social behavior change applications is their ability to connect individuals' solitary activities to a sense of audience, and related work suggests the effects of social persuasion are heightened for adolescent-focused systems [14]. These effects manifested in an interesting way in our analysis of the students' game designs: as a desire for real-time play with friends. We coded this as a desire for social presence: the sense that others are co-participating with the user in a virtual environment [33]. This was the clearest theme to emerge from our analysis. Game after game, year after year, students created games that not only required real-time participation from friends, but also made it the central focus of their games. A typical game in this respect is Fruit Frenzy, a 2011 game in which two players perform chopping motions in front of their TVs to slice oncoming virtual fruit. The game is played in person, or live, against a remote opponent, and the difficulty level matches the player's heartbeat. Players are encouraged to 'trash-talk' each other and can launch items that their opponent must dodge. During the presentation, when we asked the students how they would play if their friends weren't available, one student in the team responded: "well it has to be live, so you...play against anyone who has the game."

This trend was so strong in 2010 that we began to worry it was an artifact of the design brief itself. In 2010, in preparation for the design exercise, we showed the students several physical activity games, including Mueller's exergames, fitness games on the Wii Fit, and the Pokemon PokeWalker (a pedometer-enhanced edition of the popular Nintendo DS game). In 2011 we switched tactics and emphasized the asynchronous nature of such games. We also extended the exercise to include a round of review for each team, during which we asked the students to consider how their game might be played if their friends weren't around to play right away.

\begin{tabular}{|l|c|c|c|}
\hline Social Presence & $\mathbf{2 0 1 0}$ & $\mathbf{2 0 1 1}$ & $\mathbf{2 0 1 2}$ \\
\hline Live play only & 5 & 13 & 2 \\
\hline Live + asynchronous & 3 & 1 & 5 \\
\hline Asynchronous only & 1 & 0 & 0 \\
\hline
\end{tabular}

Table 2. Summary of Social Presence games by year.

However, despite our efforts, in 2011 students focused even more on live play to the exclusion of asynchronous play. In 2012, we made asynchronous play a cornerstone of the experience. We eliminated the initial presentation on games for health, and focused the design exercise on making a game the students could play on the StepStream platform. We also added the sentence "Remember: you and your friends may not be available to play at the same time" to the design brief and reminded the students of this point during design reviews.

These changes did have an effect; many groups, when asked, were able to adjust their games to include a solo or timeshifted play option. However our analysis of the videos shows that the students still overwhelmingly preferred real-time interaction. Of the seven games created in 2012, five supported asynchronous play. However, the student videos all focused on real-time play, with only two videos mentioning offline or solo gameplay options. A good example of this tension is City of Doom, a zombie-themed racing game in which players must escape the city in pickup trucks before the zombies catch them and turn them into zombies themselves. If a team is incomplete (that is if not all team members are online) then the game will simulate their presence by replaying their most recent race. However, these offline players will not be able to assist the live players.

\section{1) Social Presence: Design Strategies}

We weren't surprised that students in our study valued realtime play with each other; after all, that is the basis for traditional playground games. But as designers of social health applications for this audience, this finding presents a conundrum. Many social media are built around asynchronous interaction. While they support real-time chat, sites like Facebook and Twitter are primarily designed to be used and useful whenever an individual has the time to log on. And we know that in StepStream, apart from the initial registration session, students were rarely online simultaneously. Students logged in at different times, from home and at school.

And so we are left with a design tension: the realities of social media use vs. the gameplay practices and desires of our participants. If we want to leverage social media platforms for health game experiences, the games are going to have to support asynchronous play; and yet, if we want to use play as a reward and a collective bonding experience around health activity, the most rewarding games may be the ones played real-time.

\section{$B$. Incentives}

Another feature of many social health behavior change systems is the incorporation of incentive structures. Socially visible rewards can help motivate participants, and many youth-focused systems rely heavily on 'gamification' mechanics that provide badges or currency for desired activity [7]. However, designers of pervasive systems that rely on rewarding out-of-game activity (sensed or self-reported) must approach incentives differently.

Indeed, we were particularly interested in how or whether students would adapt traditional incentive structures in designing games for health, where the goals are different from those of traditional leisure games. In a game for health, the game itself may be used as a reward for desired behavior, in which case the incentive structures are inverted; the game's role is to incentivize offline physical activity, so participants spend points to play, rather than earning points through play.

In 2010 and 2011, however, most students focused on inperson physical activity games - exertion interfaces - in which the game rewards physical effort the same way a traditional videogame rewards button-mashing or simple timing. For example, in the 2011 game Fit Ninja, players simulate karate moves in order to score virtual hits on their opponents. However, in the 2012 exercise, the students were directed to design a game on top of StepStream, a system that already had a built-in 'activity points' incentive system. And indeed students seemed to grasp this different incentive structure quite naturally; all of the games from 2012 used the activity points to alter gameplay.

Some 2012 games used the activity points to provide extra boosts or 'powerups' during a more traditional incentive 
structure. In CryptoRacer, a fantasy racing game from the 2012 camp, players with sufficient activity points would be eligible to pick up speed boosts and weapons scattered throughout the race track. In Speed Mania, a running simulation from 2012, a player's activity points determined his default running speed.

Other games used activity points as a currency for purchasing in-game items. This idea is the one incentive structure we saw frequently across all three years. In Step $2 \times 5$, a lightly competitive dance and singing game from 2012, players could use activity points to get additional songs to sing and dance moves for their avatars. Model Me and iMini, two lifestyle simulation games from 2011, both rewarded physical activity with in-game items, such as virtual dresses and makeup.

In 2012, we also saw some interesting twists on incentive structures, even including altruistic uses of points. For example, City of Doom (the zombie themed racing game) allowed a player to 'rescue' another player whose car had crashed, but only if the rescuer had enough activity points. Another 2012 game - Flowball — even used activity points to alter the physics of the game world. Flowball is a two-player basketball game with a twist: the game takes place underwater. In a head-to-head game of Flowball, the water currents favor the player with the most activity points, making it easier for that player to score.

\section{1) Incentives: Design Strategies}

In contrast to social presence, students' understanding of incentive structures was more malleable, and the experience of using StepStream allowed them to visualize the game's role in incentivizing everyday activity more clearly. Students were able to understand and articulate games in which out-of-game activity is incentivized with in-game rewards. This finding suggests that designers have more freedom to experiment with incentive structures in social games for health for this population, as long as the incentives are clearly explained and connected to rewards.

\section{Gender effects}

Many commercial games, especially those aimed at children, are explicitly gendered in their approach. This can be an advantage (as ChickClique shows [34]), but what if a designer or researcher wanted to create a pervasive social health game for boys and girls in a given age group? Would it even be possible? Our findings suggest some significant gender-related challenges, but also some possible solutions.

The most bizarre concept across all three years was a game called Roger Dat. In their presentation, the team (made up of three girls and one boy) described Roger Dat as "a fun exciting military game...you get to do all sorts of cool things like picking your theme, dressing your avatar, picking the type of war and much more." Gameplay featured live combat with guns and swords, but players could also pause the game to switch outfits, and use their in-game kill points to buy new fashionable clothes and accessories for their avatar.

What was going on here? Roger Dat was a compromise, an ungainly solution to a pitched battle between the three girls and the one boy on the team. From the beginning, the girls wanted to create a collaborative hangout space where players could chat, modify their avatars, and give each other gifts. The boy was uncompromising; he would not be party to such a game; only a fighting game would do. In the end they agreed to disagree. Roger Dat was a casualty of gender effects.

In his book The Art of Game Design, Jesse Schell describes characteristics that make a game more masculine or feminine. According to Schell, masculine games emphasize mastery, competition, destruction, spatial puzzles and trial \& error, while feminine games feature emotion, real-world settings, nurturing, dialog and verbal puzzles and learning by example [35]. Seen through this lens, Roger Dat makes complete sense. The boy wanted a competitive destruction game, while the girls wanted a real-world nurturing environment focused on dialog.

To help us tease out the gender effects in students' games, we modeled our analysis after Kafai's 'design feature' technique [36]. We looked at features such as genre (Kafai found that boys tend to prefer "adventure" games with questing and achievements) and level of fantasy (girls in Kafai's studies preferred more realistic settings). We also looked for Schell's characteristics, particularly mastery, competition and dialog. We then labeled each game 'highly masculine,' 'mildly masculine,' 'mildly feminine,' or 'highly feminine.'

\begin{tabular}{|c|c|c|c|}
\hline Gendered Features & $\mathbf{2 0 1 0}$ & $\mathbf{2 0 1 1}$ & $\mathbf{2 0 1 2}$ \\
\hline Highly masculine & 2 & 6 & 2 \\
\hline Mildly masculine & 4 & 3 & 4 \\
\hline Mildly feminine & 1 & 3 & 0 \\
\hline Highly feminine & 2 & 2 & 1 \\
\hline
\end{tabular}

Table 3. Summary of games by gendered features by year.

The most highly-feminine game design was a 2011 game called iMini. This game was a virtual world that rewarded physical activity with trips to a virtual shopping mall. The game comes with several sensors (all pink) and players are directed to perform their exercises in front of a webcam. Their avatar then reflects their movements in the virtual world, and grows and shrinks as they gain or lose weight. At the end of their presentation, the four girls who designed it all chanted "Better figure, better clothes, better life, better you. iMini will be your genie!" This game contained more feminine characteristics than any other. While it rewarded mastery, it did so through dialog and real-world scenarios. The poster and game items were also all pink and purple, and all the pictures of players were female.

On the other end of the spectrum, a 2010 game called Reality Into Virtuality offered players the chance to hunt virtual animals in a safari simulation. Players would step into a spherical hamster wheel, allowing them to run and look around for prey. While the six boys who presented the game were quick to mention that the guns in the game were merely "stun guns", this game was a prototypical masculine game, focused on mastery, competition, adventure, fantasy, questing and achievements.

We also saw some evidence that students were aware of the highly gendered nature of many videogames. One 2011 game-Princess Warriors - even appeared to toy with gender roles intentionally. The three boys who presented the game described it this way: 
"Do you want a game with action? (Yes) Do you want a game with princesses? (Maybe) Then you should play Princess Warriors. Studies show that Princess Warriors should be played by obese ladies and vicious guys!"

However, this game hardly subverted gender roles; instead, the inclusion of the princesses served to reinforce the masculine nature of the game, and a gameplay analysis backs this up: the game consisted of violent fantasy fighting, and involved direct competition and mastery.

One note: when we talk about 'gendered' games, we use that as shorthand for specific masculine and feminine archetypes, not a deterministic statement of exclusivity. Indeed, in our study we saw both boys designing feminine games \& girls designing masculine games.

\section{1) Gender Effects: Design Strategies}

Despite the prevalence of gender effects in students' games, our experience from the $2012 \mathrm{camp}$ shows that gendered game design issues can be addressed, although not altogether eliminated. Racing is an interesting genre solution because it can accommodate some traditionally masculine design elements (competition, muscle cars, athleticism) without requiring others (gore, fighting, war). The racing metaphor has been used in other health games - such as the American Horsepower Challenge - and we believe its' relative genderneutrality is a big reason.

When it comes to gender effects for these types of pervasive health games, designers are left with several options: design separate games for boys and girls, and risk fragmenting the population (and alienating boys who like feminine games and girls who like masculine games); design one game with modifiable 'skins' so participants can choose to add their own gender expression to the game; or design one game with universal appeal. But we should not forget the lesson of Roger Dat: mix gendered gameplay elements carefully, or the result might be a game nobody wants to play.

\section{Competition}

Competition in a youth-focused social health intervention can be a strong motivator for some students. Indeed previous studies have shown competition-focused systems to have great promise [37]. But competition may not be the best approach for every system, and we wanted to understand its role with more nuance. Our results show that students are willing to consider a wide range of competitive and collaborative mechanics. This category is also intertwined with gender effects; on average, boys tended to design more directly competitive games, while girls tended to more collaborative ones.

Students approached competition in their games in diverse ways. In our analysis, we identified four competition types, covering a spectrum from direct competition to noncompetitive collaboration. We also identified games that contained elements of both: 'side-by-side' competitions and competitive collaboration games.

In 2011 in particular, we saw many designs that were directly competitive. Boxing game Knuckle Up, for example, allows two players using motion-sensing boxing gloves to compete against each other in a virtual knockout contest, whether they were together or at different houses. At the other end of the spectrum, several designs were not competitive at all, and instead focused on collaboration. In Model Me, a lifestyle simulation game from 2011, play primarily consisted of hanging out with friends and playing dressup with their avatars.

\begin{tabular}{|c|c|c|c|}
\hline Competition Type & $\mathbf{2 0 1 0}$ & $\mathbf{2 0 1 1}$ & $\mathbf{2 0 1 2}$ \\
\hline Direct (versus) competition & 1 & 7 & 1 \\
\hline Side-by-side competition & 6 & 3 & 4 \\
\hline Competitive collaboration & 1 & 3 & 4 \\
\hline Non-competitive collaboration & 2 & 1 & 1 \\
\hline
\end{tabular}

Table 4. Summary of games by competition types by year.

Some games contained elements of collaboration and competition, often encouraging collaboration against a common enemy. For example, in 2011's Alligator Swamp, one player is the alligator and the others are frogs. Play occurs on a large sensor mat divided into 'lilypad' squares and 'water' squares. The frogs can only move on the lilypads and the alligator can only move on the water squares. In the game, frogs work together to outwit the alligator but also compete against each other to be the last player standing.

\section{1) Gender Effects: Design Strategies}

We also identified a set of game designs that - while competitive - seemed to focus less on the competition than on side-by-side experience. Many of these were racing games. Interestingly, although these could be seen as directly competitive (and indeed many commercial racing games are), in their presentations students tended to focus on the fun of racing together rather than the thrill of coming in first. We coded most racing games as 'mildly masculine' because they included competition and fantasy (both traditional attributes of masculine games) but the focus tended to be social presence rather than achievement or mastery. Indeed, while competition is traditionally seen to be a masculine trait in games, our findings show that girls may be willing to accept competitive games if other aspects of a game are less traditionally masculine.

An interesting example of this is TriRace, a game from 2012 designed by three girls. Initially, two of the girls wanted to create a collaborative construction game much like MineCraft, but the third girl was uninterested and wanted a more competitive design. They settled on a racing game that encouraged social interactions rather than winning. In their video, the girls advertised the key benefit of TriRace this way: "You can race with other people on a bike, in a car, or just running." Based on their presentation and our informal interviews with the team, the girls seemed to view their racing game as an excuse for social interaction, rather than a chance for achievement.

The gendered nature of competition in pervasive health games is an important consideration, and work in the health promotion literature has shown this to be a concern with similar populations to our participants (lower-income, predominantly African American middle school children) [38]. However, over the course of this study we have seen some evidence that gender effects in competition can be mitigated, through indirect or 'side-by-side' competition. 


\section{DISCUSSION}

In addition to the four main themes uncovered in our analysis, we have also learned much about designing and deploying research systems: the tensions in designing games for pervasive health deployments, the advantages of our deployment-with-design strategy, and finally the importance of participatory design when designing for lower-income youth.

\section{A. Design conundrums}

The rhetoric of 'play' has considerable power for pervasive health interventions, but some challenges remain. Games can take a topic like physical activity and make it actionable and reasonable. A game setting allows kids to be a little bit weird and engage with an otherwise sensitive topic. However, pervasive health behavior change applications may make it harder to deploy the live interaction students valued so highly. This tension creates a design conundrum: how can we support the social presence students wanted while also supporting the asynchronous interactions that are more likely to occur? Moreover how can we reward offline physical activity as part of a shared social activity?

Additionally, correctly aligning rewards and incentives to encourage low-activity players requires careful thought, particularly when it comes to rewarding physical activity. A strict steps = points approach would reward the already active, making competition less appealing and undermining behavior change goals for those with below-average activity baselines. We hope others can use our experiences and design strategies to identify the challenges that matter.

\section{B. Deployment with design}

In 2012, we took the relatively unusual step of deploying a pervasive health system for several weeks primarily as an aid for participatory design exercises. In 2010 and 2011, we had seen indications of the themes presented in this paper, especially incentives and social presence, and we wondered whether these were merely due to the way in which we had framed the design problem during the first two years of the study. So in 2012 we deployed the StepStream system to aid students in their role as informants, rather than as testers. Although we did collect students' feedback about the usability and desirability of the system, we were much more interested in how it informed their design thinking.

Comparing students' designs in the years before the deployment against their designs in the 2012 exercise, we saw their adaptability to StepStream's incentive structure. In previous years, many games rewarded live exertion with ingame points. However, in StepStream, students are rewarded for walking with activity points, that the students could put to use in their game designs. Conversely, our deployment-thendesign approach revealed the persistence of students' desire for live social play. Even after having used a system where few users were on simultaneously, students still designed with live interaction first. In these ways, we believe the deployment helped us understand students' perspectives more deeply, and we recommend it to others investigating this space.

\section{Designing for by designing with}

Students shared much more with us than just their perspectives on fitness games. Throughout this project, students occasionally gave us glimpses into their own daily lives. In one particularly poignant game design from 2011, a group of three boys presented a game called How To Be $A$ Man. In this game, the player's father has recently gone to prison or died (both descriptions were used in the presentation), and now the player must become the man of the house. In the game, the player becomes more fit through exer-gaming so "he can defend his family and be the man of the house." The game also allows the player to learn marketable skills so he could earn money to support his family.

We also saw reflections of students' socio-economic status in other game designs. Several games allowed players to earn real-life money and gifts through gameplay. For example, in one game design from 2010, a group of three girls presented a game called Model Me. This game helped players to "find a job and get money, compete in pageants and earn prizes." Players could then collect that money for use in the real world. In another game from 2010-The Exercise Game-players could convert activity points into money for the bus "so if you don't have money you can just walk more so you can get where you need to go" or for use as currency in real-world stores.

Students also reflected their surroundings to us. In several of the 2012 racing games, students drew roads and cityscapes for use as backgrounds in their videos. All of these featured cracks in the sidewalk, potholes in the streets and crumbling buildings.

There are no easy design implications to be taken here. Should we incorporate crumbling buildings in our game designs? Such a direct approach might trivialize these students' life experiences; indeed we suspect our participants would rather a pervasive health game provide a brief respite from these troubles. For us as researchers, the main lesson participants in this study have taught us is this: that the only honest way to design for is to design with.

\section{CONCLUSIONS \& FUTURE WORK}

In this paper we have described a set of design strategies, conundrums and possible paths forward for creating social media games to incentivize healthy physical activity. Catalyzing behavior change when there is little external recognition of the need to change behavior is a tricky venture. Collective online social experiences that reward offline healthy behavior and that are fun and engaging have unproven potential. The demand is for our community to work with these possible users and translate this potential into effective and sustainable experiences.

Based on our findings from our three-year exploration using participatory design techniques, we know we're on the right track. In our current work, we are already putting these design strategies to use, designing systems and games our participating students will use in daily life. We plan to deploy one or multiple games for long-term evaluation in the following year. Throughout this work, we will be guided by the design implications presented in this paper, and we believe 
other research teams will find our results useful as we all explore this rich and impactful design space.

\section{ACKNOWLEDGMENTS}

We would like to thank the National Science Foundation, our many participants and our collaborators for collectively making this research possible.

\section{REFERENCES}

[1] S. Caprio, "Treating Child Obesity and Associated Medical Conditions," The Future of Children, vol. 16, no. 1, pp. 209-224, 2006.

[2] C. B. Ebbeling, D. B. Pawlak, and D. S. Ludwig, "Childhood obesity: public-health crisis, common sense cure.," Lancet, vol. 360, no. 9331, pp. 473-482, 2002.

[3] A. C. Skinner, M. J. Steiner, and E. M. Perrin, "Self-Reported Energy Intake by Age in Overweight and Healthy-Weight Children in NHANES, 2001-2008," PEDIATRICS, Sep. 2012.

[4] I. Bogost, Persuasive games: The expressive power of videogames. 2007.

[5] A. D. Miller, E. Poole, Y. Xu, E. Eiriksdottir, D. Kestranek, R. Catrambone, and E. Mynatt, "The work of play: supporting a pervasive health behavior change intervention for us middle school students," CSCW'12: Proceedings of the ACM 2012 conference on Computer Supported Cooperative Work, Feb. 2012.

[6] Y. Xu, E. S. Poole, A. D. Miller, E. Eiriksdottir, D. Kestranek, R. Catrambone, and E. D. Mynatt, "This is not a one-horse race: understanding player types in multiplayer pervasive health games for youth," presented at the CSCW '12: Proceedings of the ACM 2012 conference on Computer Supported Cooperative Work, 2012.

[7] S. Deterding, "Just add points ?," Europe, 2010.

[8] S. Deterding, "gamification and its discontents cbn," 2010.

[9] Y. Wang, M. A. Beydoun, L. Liang, B. Caballero, and S. K. Kumanyika, "Will all Americans become overweight or obese? estimating the progression and cost of the US obesity epidemic.," Obesity (Silver Spring, Md.), vol. 16, no. 10, pp. 2323-2330, 2008.

[10] S. Consolvo, D. McDonald, and T. Toscos, "Activity sensing in the wild: a field trial of ubifit garden," presented at the Proc. CHI 2008, 2008, pp. 1797-1806.

[11] Fitbit Inc., "Fitbit," fitbit.com, 30-Nov-2011. [Online]. Available: https://www.fitbit.com/. [Accessed: 30-Nov-2011].

[12] S. Consolvo, K. Everitt, J. A. Landay, and I. Smith, "Design requirements for technologies that encourage physical activity," Proc. CHI 2006, p. 457, 2006.

[13] J. Lin, L. Mamykina, S. Lindtner, G. Delajoux, and H. Strub, "Fish'n'Steps: Encouraging physical activity with an interactive computer game," UbiComp 2006: Ubiquitous Computing, pp. 261$278,2006$.

[14] S. Berkovsky, M. Coombe, J. Freyne, D. Bhandari, and N. Baghaei, "Physical activity motivating games: virtual rewards for real activity," pp. 243-252, 2010.

[15] M. A. Adams, S. J. Marshall, L. Dillon, S. Caparosa, E. Ramirez, J. Phillips, and G. J. Norman, "A theory-based framework for evaluating exergames as persuasive technology," pp. 1-8, 2009.

[16] M. U. Bers, "Civic Identities, Online Technologies: From Designing Civics Curriculum to Supporting Civic Experiences," John D and Catherine T MacArthur Foundation Series on Digital Media and Learning, pp. 139-159, 2008.

[17] M. U. Bers, "New Media for New Organs," The Journal of Research into New Media Technologies, pp. 1-17, 2008.

[18] S. J. Brown, D. A. Lieberman, B. A. Gemeny, Y. C. Fan, D. M. Wilson, and D. J. Pasta, "Educational video game for juvenile diabetes: results of a controlled trial," Informatics for Health and Social Care, vol. 22, no. 1, pp. 77-89, 1997.

[19] F. Mueller, S. Agamanolis, R. Picard, H. C. Group, and S. H. Lane, "Exertion Interfaces: Sports over a Distance for Social Bonding and Fun," Human Factors.

[20] E. S. Poole, A. D. Miller, Y. Xu, E. Eiriksdottir, R. Catrambone, and E. D. Mynatt, "The Place for Ubiquitous Computing in Schools : Lessons Learned from a School-Based Intervention for Youth Physical
Activity," Proceedings of the 13th ACM international conference on Ubiquitous Computing - Ubicomp '11, pp. 395-404, 2011.

[21] J. Sirard and R. Pate, "Physical activity assessment in children and adolescents," Sports Medicine, vol. 31, no. 6, pp. 439-454, 2001.

[22] A. Clement, "What Is Participatory Design?," Computer Professionals for Social Responsibility, 16-Sep-2012. [Online]. Available: http://cpsr.org/issues/pd/introInfo/. [Accessed: 16-Sep-2012].

[23] F. Kensing and J. Blomberg, "Participatory design: Issues and concerns," Computer Supported Cooperative Work (CSCW), no. 1993, pp. 167-185, 1998.

[24] A. Druin, "The role of children in the design of new technology," Behaviour and Information Technology, vol. 21, no. 1, pp. 1-25, 2002.

[25] H. Hutchinson, W. Mackay, B. Westerlund, B. B. Bederson, A. Druin, C. Plaisant, M. Beaudouin-Lafon, S. Conversy, H. Evans, H. Hansen, N. Roussel, B. Eiderbäck, S. Lindquist, and Y. Sundblad, "Technology probes: inspiring design for and with families," Proceedings of the, 2003.

[26] S. Yarosh, I. Radu, S. Hunter, and E. Rosenbaum, "Examining values: an analysis of nine years of IDC research," presented at the Proceedings of the 10th International Conference on Interaction Design and Children, 2011, pp. 136-144.

[27] F. Garzotto, "Broadening children's involvement as design partners: from technology to," presented at the IDC '08: Proceedings of the 7th international conference on Interaction design and children, 2008.

[28] A. Parker, V. Kantroo, H. R. Lee, M. Osornio, M. Sharma, and R. Grinter, "Health promotion as activism: building community capacity to effect social change," presented at the CHI '12: Proceedings of the 2012 ACM annual conference on Human Factors in Computing Systems, 2012.

[29] A. Grimes and R. E. Grinter, "Designing persuasion: Health technology for low-income African American communities," presented at the PERSUASIVE'07 Proceedings of the 2nd international conference on Persuasive technology, 2007, vol. 4744, p. 24

[30] J. Maitland, M. Chalmers, and K. A. Siek, "Persuasion not required Improving our understanding of the sociotechnical context of dietary behavioural change," presented at the Pervasive Computing Technologies for Healthcare, 2009. PervasiveHealth 2009. 3rd International Conference on, 2009, pp. 1-8.

[31] S. Yardi and A. Bruckman, "Income, race, and class: exploring socioeconomic differences in family technology use," Proceedings of the 2012 ACM annual conference on Human Factors in Computing Systems, pp. 3041-3050, 2012.

[32] C. DiSalvo, I. Nourbakhsh, D. Holstius, A. Akin, and M. Louw, "The Neighborhood Networks project: a case study of critical engagement and creative expression through participatory design," presented at the PDC '08: Proceedings of the Tenth Anniversary Conference on Participatory Design 2008, 2008.

[33] N. Ducheneaut, N. Yee, E. Nickell, and R. J. Moore, “'Alone Together?' Exploring the social dynamics of massively multiplayer online games," In: Proceedings of CHI 2006, ACM, New York, pp. 407-416, 2006.

[34] T. Toscos, A. Faber, K. Connelly, and A. Upoma, "Encouraging physical activity in teens Can technology help reduce barriers to physical activity in adolescent girls?," presented at the Pervasive Computing Technologies for Healthcare, 2008. PervasiveHealth 2008. Second International Conference on, 2008, vol. 8, no. 3, pp. 218-221.

[35] J. Schell, "The Art of Game Design: A book of lenses," 2008.

[36] Y. B. Kafai, C. Heeter, and J. Denner, Beyond Barbie and Mortal Kombat. MIT Press (MA), 2011.

[37] E. Eiriksdottir, D. Kestranek, A. D. Miller, E. S. Poole, Y. Xu, R. Catrambone, and E. Mynatt, "Assessment of Health Games in Secondary Schools: An Investigation of the American Horsepower Challenge 2009-2010. Georgia Institute of Technology," Georgia Institute of Technology, Atlanta, GA, USA, 2010.

[38] A. E. Staiano, A. A. Abraham, and S. L. Calvert, "Competitive versus cooperative exergame play for African American adolescents' executive function skills: Short-term effects in a long-term training intervention.," Developmental Psychology, vol. 48, no. 2, pp. 337-342, 2012. 